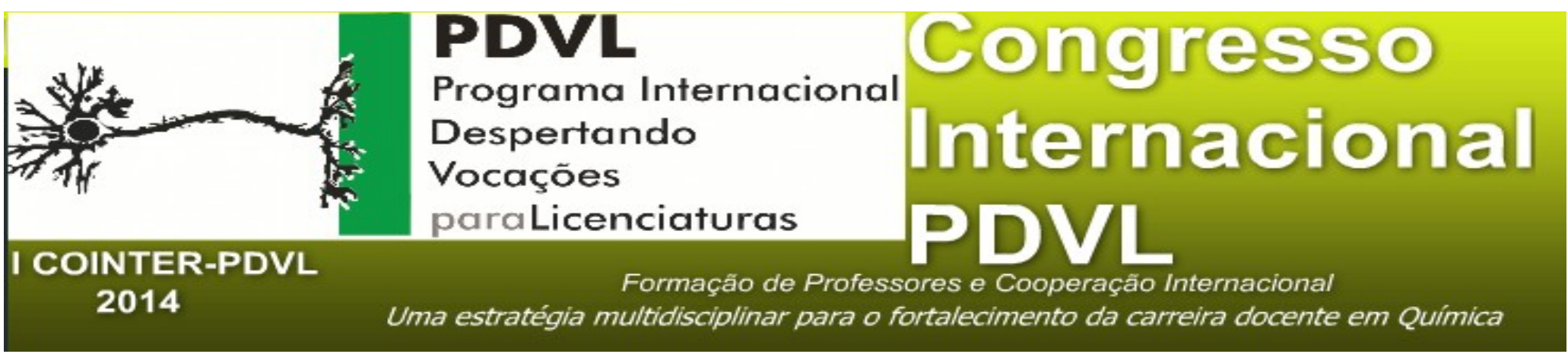

\title{
A TV PARAÍBA E A EXPERIMENTAÇÃO CIENTÍFICA NO COTIDIANO
}

Apresentação: Pôster

Paulo Ricardo Alves da Silva ${ }^{1}$; Lilian Mamedes dos Santos²; Rayssa Barbosa de Medeiros ${ }^{3}$; Jailson Machado Ferreira ${ }^{4}$

\section{Introdução}

Tendo em vista que a mídia televisiva tem sido um meio de comunicação que viabiliza de forma mais prática as informações transmitidas para sociedade, tanto de cunho social como político e científico, o Show da Química passou a ser transmitido no programa Feminíssima, um programa da televisão paraibana, com o propósito de contribuir para uma divulgação mais divertida da ciência no meio televisivo.

Dessa forma, o Show da Química na TV, desenvolvido pelos alunos do Programa de Educação Tutorial (PET) do Instituto Federal de Educação, Ciência e Tecnologia da Paraíba, busca, com as atividades experimentais, transpor o conhecimento do telespectador do senso comum para o

1 Licenciatura Plena em Química. Instituto Federal de Educação Ciência e Tecnologia da Paraíba - IFPB. Aluno bolsistas do Programa de Educação Tutoria (PET) Química. E-mail: paulo_ricardo92@hotmail.com

2 Licenciatura Plena em Química. Instituto Federal de Educação Ciência e Tecnologia da Paraíba - IFPB. Aluna bolsistas do Programa de Educação Tutoria (PET) Química. E-mail: lilian.dm@hotmail.com

3 Licenciatura Plena em Química. Instituto Federal de Educação Ciência e Tecnologia da Paraíba - IFPB. Aluna bolsistas do Programa de Educação Tutoria (PET) Química. E-mail: rayssa11@hotmail.com

4 Doutor em Química. Instituto Federal de Educação Ciência e Tecnologia da Paraíba - IFPB. Tutor do Programa de Educação Tutoria (PET) Química. Email: jailsonmf@yahoo.com.br 
conhecimento cientifico através de apresentações lúdicas, utilizando-se práticas de efeitos visuais que agucem o interesse pela ciência abordada, permitindo uma maior relação entre a teoria e a prática aplicada ao dia-a-dia.

\section{Fundamentação Teórica}

De acordo com Giordan (1999) é de conhecimento dos professores de ciências o fato de a experimentação despertar um forte interesse entre alunos de diversos níveis de escolarização. Contudo, o ensino de Química, na maioria das vezes se limita apenas à transmissão-recepção dos conteúdos, definições, leis, sem aplicabilidade e sem qualquer relação com o cotidiano vivenciado pelos alunos.

Guimarães (2009) afirma que no ensino de ciências, a experimentação pode ser uma estratégia eficiente para a criação de problemas reais que permitam a contextualização e o estímulo de questionamentos de investigação. Porém, para Ferreira (2014) a experimentação científica envolve alguns problemas, no qual a maioria dos alunos tem dificuldades para utilizar o conteúdo trabalhado nas aulas experimentais em situações extraídas do cotidiano porque as realizam em um contexto não significativo, como por exemplo uma titulação ácido-base envolvendo o ácido clorídrico e o hidróxido de sódio.

Dentro dessas questões, ao perceber a necessidade de reformular como é transmitido o ensino da Química, foi criado o Show da Química na TV, que transporta o conhecimento científico através de experimentos com efeitos visuais atrativos e significação contidiana para o telespectador.

\section{Metodologia}

O Show da Química na TV é realizado semanalmente, sendo executado no Programa Feminíssima na cidade de João Pessoa. Antecedendo à apresentação, são selecionados experimentos que apresentem efeito visual atrativo, dentre outros, que envolvam mudança de coloração, fogo, explosão e/ou reações químicas mais simples, que tenham relação, em sua maioria, com 
experiências que vivenciadas no cotidiano. Após o término de cada experimento faz-se uma explicação contextualizada.

\section{Resultados e Discussões}

Os experimentos realizados no Show da Química na TV proporcionam uma maior interação entre os expectadores e a ciência química, visto que as práticas apresentadas contêm efeitos visuais capazes de despertar a atenção e provocar encantamento e curiosidades. Logo, a atividade desenvolve novas competências para o ensino-aprendizagem de Química, ocasionando a compreensão do conhecimento teórico, uma vez que busca-se correlaciona-los com situações do cotidiano.

As apresentações dessa atividade no programa televisivo também contribuem de maneira significativa na formação dos integrantes do PET Química, visto que o grupo é constituído por licenciandos e, dessa forma, os mesmos tem a chance de desenvolver habilidades docentes essenciais na vida profissional. Além das vantagens supracitadas, o Show da Química na TV propicia também uma maior interação entre a Instituição de Ensino Superior e a comunidade.

\section{Conclusões}

Tendo em vista que a experimentação em química é uma estratégia eficiente para a criação de problemas reais que permitam a contextualização e o estímulo de questionamentos e investigação, a atividade possibilitou aos telespectadores uma melhor interação da química com o seu cotidiano, através da explicações de conhecimentos científicos presentes no dia a dia, de forma dinâmica, fugindo da metodologia tradicional aplicada atualmente no ensino de Ciências. Portanto a explanação desses experimentos possibilitaram um processo de ensino-aprendizagem mais significativo, destacando a importância da utilização de novas metodologias e instrumentos de aprendizagem para o ensino de ciências.

\section{Referências}

FERREIRA, Luiz Henrique; HARTWIG, Dácio Rodney; OLIVEIRA, Ricardo Castro de. Ensino Experimental de Química: Uma Abordagem Investigativa Contextualizada. Química Nova na 
Escola, v. 32, n. 5, mai. 2014.

GIORDAN, Marcelo. O papel da experimentação no ensino da ciência. Química Nova na Escola, n. 10, nov. 1999.

GUIMARÃES, Cleidson Carneiro. Experimentação no Ensino de Química: Caminhos e Descaminhos Rumo à Aprendizagem Significativa. Química Nova na Escola, v. 31, n. 3, ago. 2009. 